\title{
The Impact of Human Resource Development on Economic Development in Sudan "in the Period from 2007 to 2017"
}

\author{
Ahmed Mohammed Bilal ${ }^{1}$, Nahid Alamin Ibrahim ${ }^{2}$ \\ ${ }^{1}$ Economics Department, Port Sudan Ahlia College, Port Sudan, Sudan \\ ${ }^{2}$ Languages Department, Ahlia College, Port Sudan, Sudan
}

Email address:

ahmedblal@yahoo.com (A. M. Bilal), nahidibrahim7272@gmail.com (N. A. Ibrahim)

\section{To cite this article:}

Ahmed Mohammed Bilal, Nahid Alamin Ibrahim. The Impact of Human Resource Development on Economic Development in Sudan "in the Period from 2007 to 2017". International Journal of Environmental Chemistry. Vol. 4, No. 1, 2020, pp. 20-27.

doi: $10.11648 /$ j.ijec.20200401.13

Received: June 17, 2019; Accepted: September 16, 2019; Published: February 4, 2020

\begin{abstract}
The study dealt with the impact of human resource development on the economic development in the Sudan. It is one of the most important problems of development failure. The weakness of human capacity and the absence of the administrative system is a major obstacle to development plans. Therefore, the success of economic development depends on the human element. What are the difficulties that affect the development and performance of human resources and how to use human resources in an optimal way and to benefit from them in achieving economic development. The most important recommendations are: a. Attention should be given to increasing training opportunities, namely, human development; b. Increasing gross domestic product (GDP) of economic development, which include.
\end{abstract}

Keywords: Economic Development, Human Resource, Training, Society, Natural Resources

\section{Introduction}

Human resources are the main wealth of the nations of the physical capital and natural resources, despite the importance and necessity, but without the human element efficient and well-trained and will not be so valuable because people are able to use these resources and use in the production processes to obtain the maximum satisfaction possible to achieve Well-being is the human element with its ability to invent, innovate and develop through which scarcity of natural resources can be limited and expand the productive potential of society. There is no doubt that human resources are a prerequisite for achieving comprehensive development. The definition of economic development also: It is an interactive process during which the real national income of the state as well as the average per capita income during a certain period of time, that is, the process of economic development is an administrative process aimed at increasing real national income and individual for a long period of time Omar Hussein (1985). A country that is unable to develop its human resources cannot achieve its desired goals. It has been proven that human mind and effort lead to progress and progress. It is necessary to provide capital and independence of natural resources, Trade exchange etc..... For example, there are countries with simple resources, yet developed countries Britain, for example, was the largest economic power in the world and did not have any natural sources before the discovery of the North Sea and Switzerland not only owns waterfalls and Japan has only modest amounts of coal, The development of human resources is a priority in the process of developing human resources. Planning it as one of the most important factors that contribute to speeding up the process of overall economic development. Gross domestic product (GDP) is the sum of goods and services produced by members of a given community living within the geographical area of that country irrespective of their nationality, whether they are nationals of the country or foreigners within a particular year. In addition to this, attention should be paid to the human element and to the adoption of educational policies that are compatible with the requirements of human development in terms of the qualitative and quantitative need in the labor market, in addition to the attention to training programs and the development of manpower skills and providing them with the required capabilities in the fields of work and development and keeping pace with technical developments. 
Search problem. Lies in how to develop human resources to serve economic development. The problem of research is by answering the following questions:

1. What are the difficulties affecting the development and performance of human resources on economic development?

2. What are the most important means of developing human resources and how are they used to serve economic development efforts?

3. How to use human resources optimally and make use of them in achieving economic development?

4. Is the implementation of strategic plans reflected negatively or positively on human and economic development?

\subsection{Importance of Research}

It is important that the development of human resources is an important element in the productive process in society, and even more important than any of the other material assets that the society possesses because the human element is the target of development programs because it is the main element in the process of construction and economic and social progress. A state that is not only the resources it possesses or the oil reserves inherent in it, nor the financial surpluses it stores as much as the quality of working human beings and the creation of human capital (intellectual). The importance of this research lies in shedding light on human resources and their impact on economic development.

\subsection{Research Hypotheses}

1. Does human resource development affect economic development?

2. Are the objectives of the Strategic Plan an impact on human development and economic development?

3. Does internal and external training affect GDP?

4. Do you consider implementing the performance of strategic plans to have an impact on human and economic development?

\subsection{Research Goals}

1. Study the relationship between human development and economic development.

2. Highlight the importance of training in the development of human and economic resources.

3. Give a clear picture of human resources and their impact on economic development.

Research Methodology:

Use the method of descriptive statistics and inductive and deductive analysis and then draw conclusions and recommendations.

\subsection{Methods}

By collecting data from books, references, reports, periodicals, scientific journals, conferences, seminars, and the Internet

\subsection{Research Limits}

Spatial Limits: Republic of Sudan Time Limits: 20072017.

\section{Literature Review}

\subsection{The Concept and the Importance of Economic Development}

Different opinions and views of scientists, thinkers and researchers on the definition of the concept of economic development and the difficulty of agreement is due to the different intellectual and ideological trends as well as different disciplines of scientists and researchers until it became difficult to define a precise and precise development or economic growth in clear and specific terms, they believe that the reform of economic growth has It became understandable to all to the extent that it does not need a precise definition "Omar Hussein (1985). Economic thinkers and scientists did not agree on a common definition of development, but we will try to include some Definitions that came out, trying to find a common denominator for these definitions.

Economists defined development as a process of increasing real national income and steadily increasing this over a long period of time, so that this increase is greater than the increase in population, so that there is a change in the structure of the economy in the state.

While others defined it as: organized efforts, which are made according to planning and drawings to coordinate the human and material resources available in a particular social environment limit the achievement of higher levels of national income and individual incomes and higher levels of living and economic life in its various aspects such as education and health and then to achieve the highest possible level of welfare Social.

The definition of economic development as well: It is an interactive process during which the real national income of the state as well as the average per capita income over a certain period of time, that is, the process of economic development is an administrative process aimed at increasing real national income and individual for a long period of time. Mustafa Hussein \& Muhammad Shafiq (1995).

\subsection{Importance of Economic Development}

The concept of sustainable development is now popular because of the integrated relationship between environment and development and before addressing.

For this concept we try to identify the importance of economic development.

The importance of economic development is reflected in the following two elements:

First, development is a means to reduce the economic and technical gap between developing and developed countries. The latter must achieve economic and social development to advance and walk with developed countries. In this context, 
we must point out a set of factors that help to sharpen this gap, which can be limited to the following two groups.

\subsection{Economic Factors}

These factors affect the economic aspect, namely:

1. Economic dependency abroad.

2. Rule of single production mode.

3. Weak industrial structure.

4. Weak agricultural structure

5. Lack of capital.

Human Development Concept. The United Nations Development Program (UNDP) has played a leading role in adopting and promoting this concept in the Human Development Reports issued since 1995. This concept has received attention from those interested in social sciences. Some believe that the history of human development dates back to classical and non-classical economic schools from the mid-18th century to the 20th century. However, the concept of these schools is different from the concept in its new state. The first: the work was considered a production element that reflects growth and progress, while the new concept considered human essence of development that development must respond not only to economic requirements, but It also defines human and political development and defines human development in the UN reports as (expanding options available to people). a. Access to knowledge b. long and difficult life. Access to the necessary resources to provide an adequate standard of living.

\subsection{Human Development Has Two Aspects}

Building human capacity to improve health, knowledge and skills.

Second: the use of the people acquired in the spare time and for the purposes of production and activity in the field of culture, society and politics, and therefore income is not one of the options and the annual increase in the national product is a necessary condition for human development means human development in society development in all its areas where human forces are the mainstay of society and the pillars of any events. The development of society We must pay attention to its development in all aspects of economic, cultural and political and the advancement of the lives of these human forces, which will in turn lead to the advancement of society and build a civilization that achieves prosperity. Mohammed Ahmed Hassan Ibrahim, (2007).

\subsection{The Concept of Human Capacity and Human Capital}

There is no doubt that the concept of human capacity and human capital are interdependent and interrelated, but this interdependence and overlap does not mean that they are equal, the increase in productive capacity is an increase in the level of education, for example, and the concept of human capital basically means to improve the standard of living or increase income resulting from increased production in reading And communicate with people in defense of their rights. Human capital can be defined as all that increases the productivity of workers and employees through the cognitive and technical skills they acquire through science and experience, and we add that the concept of human capacity is not only more comprehensive than the concept of human capital, but different beliefs in the belief that the human It is the goal of capital growth in its various forms. Rather than considering capital as a goal for human growth, it is economic growth according to the concept of human capacity, it is to increase the area of freedom available to human beings to live the life of their choice and. appreciation. Zaki Ismail,,(2009), Methods of measuring human development: Due to the great similarity, which is almost identical between the two estimates of human development for the years (1995-1997) in relation to the concept and content of human development and because the most important considerations of humanity under the standards of human development is the long life free of diseases and to know the income necessary for a decent life. Human development is measured by the Human Development Index (HDI), called the Human Development Index (HDI), which represents a composite index of deprivation.

\subsection{Human and Human Progress Simultaneously}

It consists of three indicators:

(i) Longevity: measured by life expectancy at birth.

(ii) Knowledge: Adult literacy is measured.

(iii) A decent and decent life, measured by income and resources.

The first indicator through the life expectancy variable is based on three considerations of the true value of longevity and its value in helping people to achieve different goals and its relation to other characteristics such as good health and good nutrition.

The second indicator of knowledge is a general reflection of access to quality education opportunities, which is essential for productive life and is measured through adult literacy, as literacy is only a basic first step in education, knowledge acquisition, and human development measures. The GenderAdjusted Human Development Index (GD), which measures the level of state achievement in human capacity development in the three previous areas, taking into account inequities in the distribution of these capacities among males and females. So that human gift items worth decreases the greater the disparity between the shares of males and females. The average level of achievement reference for each of the three criteria should be calculated to reflect the per capita share of both males and females instead of using a single level of society as a whole that does not reflect the gender distribution: First: Calculate the average overall achievement in a particular field. Second: the relationship of achievement to welfare. Third: Calculate the level of achievement equivalent to the equitable distribution. Fourth: Educational attainment and justice. Fifth: the level of income and justice. Sixth: Calculating the Human Development Index (HDI) in Gender The latest measure of human development is the Gender Modified Participation 
Index, which focuses on three variables that reflect the extent of women's participation in political decision-making, the extent of their participation in administrative and professional functions and the extent of their participation in economic resources. The following formula is used to express the equitable distribution of resources among different groups.

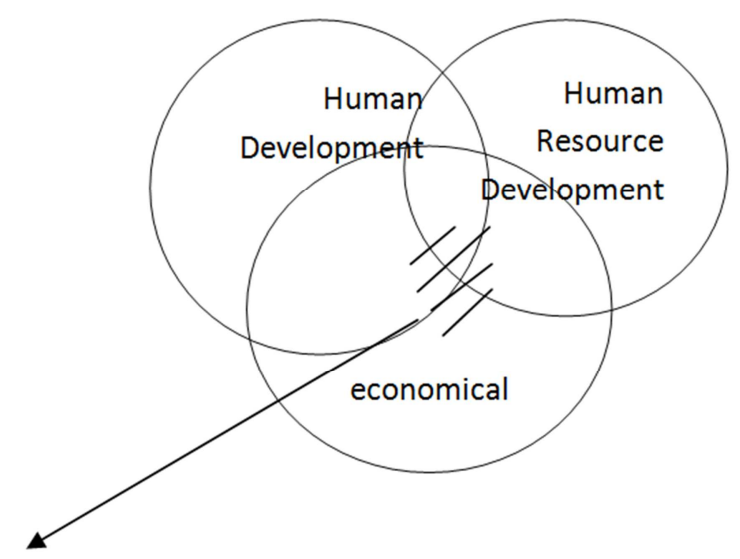

Figure 1. The interference area shows three elements.

Illustrates the interrelationship between human resources development, economic development and human development and shows the correlation between the three axes, each of which affects and is affected by the other. When human resource development increases skill and knowledge, this leads to efficient use of material resources, Means economic development and when economic development occurs, it is a good indicator of human development as it is reflected in the achievement of human development indicators of education, health and raising the standard of living by increasing the income of individuals. So this overlap zone means growth and evolution in each of the three elements. Nadia Mohammed and Riiman, (2012).

\subsection{Resources and Development}

These resources for the economic development process, also called development terms, which are considered as human resources, can be considered as necessary and work on their development is one of the most important requirements which can be highlighted as follows:

1. Natural resources: means resources such as land and natural wealth. Most developing countries suffer from lack of natural resources or will not discover their natural wealth, and if discovered, they are untapped and independent, they are not exploited optimally.

\subsection{Human Resources}

Human Resources play an important role in the development process, since the human being is the goal of development and it is an effective means of development. Human resources means the abilities, talents, skills and knowledge of individuals who can be used in the production of goods or the performance of services. Human resources work on the accumulation of capital The exploitation of natural resources, the adoption of economic policy and the pursuit of national development and the failure of development programs are the reason for the neglect of human resources development. Capital and natural resources are important factors in economic development, but the development of human resources is more important.

\subsection{Concept of GDP}

The concept of gross domestic product (GDP) is an important and widely used term. The total value of goods and services at market prices is the total value of goods produced by the economy in a given period of one year. Intermediate goods, ie used in the production of other goods, are not counted to avoid.

\subsection{Arithmetic Recurrence}

Total goods and services This is gross in the sense that the depreciation of equipment or capital used in the production of those goods and services is not deducted.

Gross domestic product (GDP) is the sum of goods and services produced by members of a given community living within the geographical area of that country irrespective of their nationality, whether they are nationals of the country or foreigners within a particular year.

\section{Methods}

\subsection{Measuring Gross Domestic Product}

There are three ways to measure gross domestic product (GDP): production, income, and expenditure.

\subsubsection{First: Production Method}

It is measured by measuring the national income measured in this way in two ways: the final goods method, in which the national income is measured by calculating the values of goods and services and their final form, which is produced in the economy during the year, Internal Value added The value of GDP is equal to the total value added in all sectors.

\subsubsection{Second: the Method of Income}

The gross domestic product (GDP) = the value of salaries and wages paid during the year + the estimated value of the housing rents inhabited by its owners + the value of the profits distributed and not distributed.

\subsection{Expense Method}

This method focuses on calculating all aspects of spending in the economy, which are represented in household spending, private sector spending, government spending and net spending.

Real and nominal GDP.

The change in GDP is usually the result of price changes rather than the change in the same output. GDP is measured by market prices, which is called nominal or cash GDP, while measured at constant prices called GDP. 


\subsection{Relationship Between Economic Development and GDP}

The application of economic development and study in the twentieth century was based on the understanding of a set of criteria and indicators used to deal with countries, especially developing ones, which led to the need to activate the role of measurement in understanding the economic development of these countries. The economic development index uses a range of means and indicators to measure the success of economic development in society. Gross Domestic Product (GDP).

The calculation of its value is one of the methods used to calculate the gross domestic product and helps to identify the nature of the success of economic development in the country if it refers to the value of goods and services produced and used in the trading market, which apply to the sales and purchase and regular. (8). htll: www.mohe.gov.sd. Website.

\subsection{Economic Strategy for the Development of Human Resources in Sudan}

This concept means crystallizing and realizing the national strategic economic interests in the Sudan in light of the challenges at the global, regional and local levels, and possessing the strategic economic capacity and the optimal utilization of the resources, the most important of which is human resources, its development, development of new resources, conservation of the environment, balanced development and food security.

Table 1. Internal training in Sudan by field for the period (2007-2011).

\begin{tabular}{|c|c|c|c|c|c|c|c|c|c|}
\hline \multirow{2}{*}{ Areas } & \multicolumn{3}{|l|}{2007} & \multicolumn{3}{|l|}{2008} & \multicolumn{3}{|l|}{2009} \\
\hline & academic & Practical & ratio & academic & Practical & ratio & academic & Practical & Ratio \\
\hline Financial & 0 & 47 & 0.42 & 1 & 29 & 0.27 & 0 & 4 & 0.04 \\
\hline Administrative & 12 & 36 & 0.01 & 5 & 215 & 0.03 & 6 & 168 & 0.03 \\
\hline Languages & 1 & 0 & 0.02 & 0 & 9 & 0.16 & 0 & 2 & 0.04 \\
\hline Transfer & 0 & 1 & 0.02 & 0 & 23 & 0.36 & 0 & 0 & 0 \\
\hline environmental & 1 & 4 & 0.09 & 3 & 10 & 0.24 & 2 & 1 & 0.05 \\
\hline educational & 0 & 24 & 0.38 & 0 & 22 & 0.34 & 0 & 0 & 0 \\
\hline Computer & 0 & 8 & 0.62 & 1 & 8 & 0.69 & 0 & 2 & 0.15 \\
\hline Literal & 0 & 4 & 0.31 & 0 & 6 & 0.46 & 0 & 0 & 0 \\
\hline Industrial & 0 & 5 & 0.07 & 0 & 8 & 0.11 & 1 & 1 & 0.03 \\
\hline healthy & 65 & 35 & 0.34 & 36 & 20 & 0.19 & 8 & 1 & 0.03 \\
\hline agricultural & 2 & 16 & 0.06 & 3 & 53 & 0.17 & 2 & 5 & 0.02 \\
\hline Wholesale & 91 & 201 & 2.53 & 59 & 416 & 3.19 & 24 & 184 & 0.42 \\
\hline
\end{tabular}

Table 1. Continued.

\begin{tabular}{|c|c|c|c|c|c|c|c|}
\hline \multirow{2}{*}{ Areas } & \multicolumn{3}{|l|}{2010} & \multicolumn{3}{|l|}{2011} & \multirow{2}{*}{ Wholesale } \\
\hline & academic & Practical & ratio & academic & Practical & ratio & \\
\hline Financial & 0 & 35 & 0.31 & 0 & 17 & 0.15 & 113 \\
\hline Administrative & 8 & 493 & 0.08 & 32 & 472 & 0.08 & 6442 \\
\hline Languages & 0.38 & 6 & 0.11 & 0 & 6 & 0.11 & 55 \\
\hline Transfer & 0 & 17 & 0.27 & 0 & 22 & 0.34 & 64 \\
\hline environmental & 4 & 7 & 0.2 & 1 & 22 & 0.42 & 55 \\
\hline educational & 3 & 10 & 0.2 & 1 & 4 & 0.08 & 64 \\
\hline Computer & 0 & 18 & 1.38 & 0 & 0 & 0 & 13 \\
\hline Literal & 0 & 3 & 0.23 & 0 & 38 & 2.92 & 13 \\
\hline Industrial & 6 & 8 & 0.19 & 8 & 29 & 0.49 & 75 \\
\hline healthy & 5 & 31 & 0.12 & 61 & 94 & 0.53 & 291 \\
\hline agricultural & 13 & 130 & 0.44 & 4 & 763 & 2.38 & 322 \\
\hline Wholesale & 57 & 777 & 3.8 & 133 & 763 & 7.88 & 7649 \\
\hline
\end{tabular}

Table 1 above shows the year 2007 compared to the other years. The highest percentage of financial training rates was $42 \%$, the lowest percentage in 2011 was $0.15 \%$, the highest in 2011 was $0.8 \%$ and less In 2008, the ratio of 0.1 and GATT was $0.16 \%$ and $0.34 \%$ respectively. The lowest percentage was in $2007(0.2 \%$ and $0.2 \%$ respectively) and the highest area in 2010 The ratio of $0.42 \%$ and the lowest in
2009 was $0.5 \%$. The educational and technical fields respectively were the highest in 2007 at $0.38 \%$ and the highest in 2011 was $0.37 \%$ and the lowest percentage In 2010 0.00 and $0.4 \%$.

As for the agricultural field, the highest percentage in 2011 was $2.38 \%$ and the lowest percentage in 2009 was $0.2 \%$.

Table 2. External Training in Sudan by Field for the Period (2007 - 2011).

\begin{tabular}{|c|c|c|c|c|c|c|c|c|c|}
\hline \multirow{2}{*}{ Areas } & \multicolumn{3}{|l|}{2007} & \multicolumn{3}{|l|}{2008} & \multicolumn{3}{|l|}{2009} \\
\hline & academic & Practical & ratio & academic & Practical & ratio & academic & Practical & Ratio \\
\hline Financial & 45 & 525 & 0.28 & 39 & 152 & 0.09 & 12 & 530 & 0.27 \\
\hline Administrative & 137 & 1463 & 0.21 & 42 & 531 & 0.08 & 57 & 975 & 0.14 \\
\hline
\end{tabular}




\begin{tabular}{|c|c|c|c|c|c|c|c|c|c|}
\hline \multirow{2}{*}{ Areas } & \multicolumn{3}{|l|}{2007} & \multicolumn{3}{|l|}{2008} & \multicolumn{3}{|l|}{2009} \\
\hline & academic & Practical & ratio & academic & Practical & ratio & academic & Practical & Ratio \\
\hline Languages & 11 & 185 & 0.14 & 1 & 96 & 0.07 & 4 & 112 & 0.08 \\
\hline Transfer & 1 & 16 & 0.12 & 0 & 21 & 0.15 & 0 & 34 & 0.25 \\
\hline Environment & 10 & 76 & 0.24 & 1 & 3 & 0.01 & 3 & 4 & 0.02 \\
\hline educational & 2 & 278 & 0.84 & 3 & 23 & 0.08 & 0 & 18 & 0.05 \\
\hline Technical & 17 & 707 & 0.56 & 0 & 78 & 0.06 & 14 & 382 & 0.31 \\
\hline Computer & 18 & 91 & 0.05 & 0 & 70 & 0.03 & 8 & 382 & 0.17 \\
\hline Industrial & 4 & 208 & 0.86 & 1132 & 2 & 4.59 & 2 & 39 & 0.17 \\
\hline healthy & 851 & 103 & 0.19 & 11 & 46 & 0.01 & 122 & 33 & 0.03 \\
\hline Wholesale & 1097 & 3720 & 3.76 & 1231 & 1048 & 5.28 & 223 & 2773 & 2.5 \\
\hline
\end{tabular}

Table 2. Continued.

\begin{tabular}{|c|c|c|c|c|c|c|c|}
\hline \multirow{2}{*}{ Areas } & \multicolumn{3}{|l|}{2010} & \multicolumn{3}{|l|}{2011} & \multirow{2}{*}{ Wholesale } \\
\hline & academic & Practical & ratio & academic & Practical & ratio & \\
\hline Financial & 36 & 600 & 0.31 & 2 & 92 & 0.05 & 2033 \\
\hline Administrative & 226 & 2748 & 0.39 & 60 & 1366 & 0.19 & 7605 \\
\hline Transfer & 0 & 51 & 0.37 & 0 & 15 & 0.11 & 138 \\
\hline Environment & 9 & 134 & 0.4 & 18 & 170 & 0.53 & 357 \\
\hline educational & 6 & 140 & 0.44 & 4 & 63 & 0.2 & 332 \\
\hline Computer & 12 & 1033 & 0.47 & 4 & 127 & 0.06 & 2243 \\
\hline Literal & 0 & 96 & 0.37 & 1 & 6 & 0.03 & 261 \\
\hline Industrial & 15 & 75 & 0.36 & 2 & 44 & 0.19 & 247 \\
\hline healthy & 130 & 1457 & 0.32 & 1457 & 117 & 0.32 & 4941 \\
\hline Wholesale & 613 & 7489 & 4.4 & 1557 & 2189 & 1.81 & 20871 \\
\hline
\end{tabular}

It is clear from Table 2 above that the training in 2007 compared to the rest of the years and the percentage of training in the financial field for the year $200728 \%$ and then decreased in 2009 to $9 \%$ and rose in 2010 to $31 \%$ and then decreased in 2011 to $15 \%$ and areas The following languages of transport and administrative training rate in 2007 amounted to $14 \%$ respectively and $12 \%$ and $21 \%$ and then began to decline in the years 2008, 2009, 2010, $2011 \mathrm{~m}$ respectively accounted for $4 \%, 11 \%$, then $4 \%$.

The other fields of education and technical and computer training in 2007 were respectively $24 \%, 56 \%, 5 \%$, and there is fluctuation in the other years between the rise and fall.

The share of craftsmen, industrial and health workers in 2007 reached $26 \%, 68 \%$ and $19 \%$, and then began to decline in 2008 and 2009 , reaching $32 \%, 19 \%, 3 \%$

Table 3. Internship in the period from 2014 to 2017 Capacity building in development.

\begin{tabular}{|c|c|c|c|c|c|c|}
\hline \multirow{2}{*}{$\begin{array}{l}\text { Specialization } \\
\text { the year }\end{array}$} & \multicolumn{3}{|c|}{ Administrative and human resources management } & \multicolumn{3}{|c|}{ Computer and Information Technology } \\
\hline & Course & the Apprentice & Excution percentage & Course & the Apprentice & Excution percentage \\
\hline 2014 & 184 & 5177 & 62.2 & 98 & 2664 & 204 \\
\hline 2015 & 1207 & 905 & 65.7 & 17 & 5955 & 32 \\
\hline 2016 & 13 & 291 & 83 & 5 & 114 & 46 \\
\hline 2017 & 15 & 209 & 55 & 10 & 50 & 39 \\
\hline
\end{tabular}

Table 3. Continued.

\begin{tabular}{lllllll}
\hline \multirow{2}{*}{$\begin{array}{l}\text { Specialization } \\
\text { the year }\end{array}$} & \multicolumn{2}{l}{ Financial and accounting development } & & \multicolumn{2}{c}{ Educational and social development } \\
\cline { 2 - 6 } & Course & the Apprentice & Excution percentage & Course & the Apprentice & Excution percentage \\
\hline 2014 & 43 & 943 & 14.6 & 141 & 16590 \\
2015 & 97 & 529 & 3 & 4 & 118 \\
2016 & 7 & 179 & 51 & 2 & 336 \\
2017 & 47 & 1424 & 42 & 12 & 45 & 1223 \\
\hline
\end{tabular}

The highest percentage in the field of training for the year 2014 was in the educational development of $99 \%$ and the lowest percentage of field implementation in agriculture. In 2015 the highest percentage in $65 \%$ in the administrative and human resources and the lowest proportion of environmental development amounted to $7 \%$ in $201683 \%$ implementation was the luck of management of human resources and the lowest proportion in quality and development amounted to $6 \%$ and in 2017 the highest percentage was also in the field of human resources management amounted to about $55 \%$ and the lowest in the areas of health, agriculture and the environment is almost nonexistent 


\section{Data Analysis}

Table 4. Percentage of GDP increase.

\begin{tabular}{lll}
\hline the years & Gross domestic product in millennia & Increase in GDP\% \\
\hline 2007 & 90339 & 1.41 \\
2008 & $127,716.90$ & 1.64 \\
2009 & $148,137.00$ & 1.8 \\
2010 & $162,203.90$ & 2.07 \\
2011 & $186,556.30$ & 2.69 \\
2012 & $243,412.80$ & 3.26 \\
2013 & $294,630.20$ & 5.27 \\
2014 & $475,827.70$ & 6.45 \\
2015 & $582,936.71$ & 7.39 \\
2016 & $667,568.00$ & 9.12 \\
2017 & $823,938.00$ & \\
\hline
\end{tabular}

The researcher prepared Table 4 for the rate of percentage increase in GDP through the base year 2007 as follows:

$$
\text { Increase in GDP }=\frac{\text { Comparison Year }}{\text { Base year }} \times 100
$$

Application of the ratio of increase in GDP to $2008=\frac{\text { GDP for } 2008}{\text { GDP for the year } 2007} \times 100$

$$
\frac{127746.90}{90339.0}=1.41 \%
$$

Thus, the table was prepared with Equation (1).

\begin{tabular}{|c|c|c|c|c|}
\hline strategic goals & Strategy implementation \% & $\begin{array}{l}\text { Implementing } \\
\text { internship\% }\end{array}$ & $\begin{array}{l}\text { Percentage of implementation } \\
\text { Training abroad } \%\end{array}$ & Increase in GDP\% \\
\hline the first & 48.7 & 2.53 & 3.76 & 1.41 \\
\hline The second & 61.5 & 3.19 & 5.28 & 1.64 \\
\hline the third & 15 th & 0.42 & 2.5 & 1.8 \\
\hline the fourth & 31 & 3.8 & 4.4 & 2.07 \\
\hline Fifth & 51 & 7.88 & 1.81 & 2.69 \\
\hline VI & 62 & $\longrightarrow$ & $\longrightarrow$ & 3.26 \\
\hline VIII & 61 & 6.2 & 2.5 & 6.45 \\
\hline Ninth & 77 & 25.3 & 3.33 & 7.39 \\
\hline Tenth & 75 & 3.01 & 25.25 & 9.12 \\
\hline
\end{tabular}

Table 5. The impact of human development on economic development.

\begin{tabular}{|c|c|c|c|c|c|}
\hline $\begin{array}{l}\text { Percentage of } \\
\text { implementation of } \\
\text { internship\% } \\
\end{array}$ & $\begin{array}{l}\text { Percentage of } \\
\text { implementation } \\
\text { Training abroad\% }\end{array}$ & Increase in GDP\% & $\begin{array}{l}\text { Logarithm Percentage } \\
\text { of implementation of } \\
\text { internship } \%\end{array}$ & $\begin{array}{l}\text { Logarithm Ratio of } \\
\text { implementation of } \\
\text { training abroad } \% \\
\end{array}$ & $\begin{array}{l}\text { Logarithm } \\
\text { Percentage increase } \\
\text { in GDP\% }\end{array}$ \\
\hline 2.53 & 3.76 & 1.41 & 0.4 & 0.58 & 0.15 \\
\hline 3.19 & 5.28 & 1.64 & 0.5 & 0.72 & 0.21 \\
\hline 0.42 & 2.5 & 1.8 & -0.38 & 0.4 & 0.26 \\
\hline 3.8 & 4.4 & 2.07 & 0.58 & 0.64 & 0.32 \\
\hline \multirow[t]{3}{*}{7.88} & 1.81 & 2.69 & 0.9 & 0.26 & 0.43 \\
\hline & - & 3.26 & \#VALUE! & \#VALUE! & 0.51 \\
\hline & $\longrightarrow$ & 5.27 & \#VALUE! & \#VALUE! & 0.72 \\
\hline 6.2 & 2.5 & 6.45 & 0.79 & 0.4 & 0.81 \\
\hline 25.3 & 3.33 & 7.39 & 1.4 & 0.52 & 0.87 \\
\hline 3.01 & 25.25 & 9.12 & 0.48 & 1.4 & 0.96 \\
\hline
\end{tabular}

Table 6. The impact of the development of human resources on economic development.

\section{Conclusion \& Recommendations}

Human resources development and rehabilitation have an effective impact in achieving the objectives of economic development. The most important indicators of economic are human development, then it is the development of the people who are the means and the people who are the end.

The training is weak especially in the fields of agriculture, health and the environment because of the problem of 
funding and the deviation rate of funding is very large if compared with previous years. We neglect the slow development of human resources and thus affect the economic development in Sudan.

Despite the strategies that have been put in place since 2007, it has not achieved satisfactory results, especially in the strategies that have been carried out from (20072011) and (2012-2016).

We find that the ratios are high in implementation and are contrary to the ground reality, for example strategy

In the development of education, the number of projects 77 and the implementation of 46 projects are underway in 29 projects and not implemented 2, the performance ratio $78 \%$ and that there are statistics in the pre-school education high and then mainly the decline in secondary and university. The output of education is weak compared to the labor market This leads to a shortage of human resources.

It was explained through the research that there is a gap between human resources and economic development in the Sudan, so it was necessary to pay attention to the development of human resources by increasing the knowledge and rehabilitation and training in order to contribute effectively to the process of production and then the overall economic development in Sudan and sustainable.

This proves the important role that human resource development can play in achieving economic development through its indicators of education, health and a better standard of living through increased per capita GNP.

1. There is a positive impact of statistical significance as the proportion of human resources increased the proportion of economic development.

2. There is a positive effect of statistical significance in increasing the implementation of strategic plans to increase economic development.

3. There is a positive effect of statistically significant increase in the percentage of implementation of internal and external training to increase the percentage of GDP.

4. There is a positive effect of statistical significance between the percentage of implementation of the objectives of the strategy and the proportion of human development and the rate of economic development.

The Recommendations are:

1. To pay attention to human development so that there can be comprehensive economic development.

2. Focus the strategy on guiding support for economic development through health, agriculture, livestock and the environment.

3. Increase training opportunities.

4. Take care to implement the objectives of the strategic plans that have been developed.

\section{References}

[1] Ahmed Ibrahim Abu Sun, Human Resources Department 2, Sudan Printing Press Ltd., Khartoum, 2008.

[2] Abdul Baqi Abdul Ghani Babiker, Education and Accreditation in Higher Education, Khartoum, 2009.

[3] Abdul Hamid Mohammed, unpublished research thesis, the role of knowledge finance in achieving economic development.

[4] Abu Bakr Qadim,(The impact of human resources development as a means to achieve economic development), Master Thesis in Economics unpublished, University of Nileen 2015.

[5] Ali Abdelkader Ali,(Development Economics in Sudan), 2011.

[6] Ali Abdelkader, (Modern Trends in Development, University House, Alexandria), 2000.

[7] Fayez Al-Adawi, 2002. Foundations of Human Geography, University Knowledge House, National Population Council.

[8] Falih Khalaf,(Economic Development, Amman), 2006.

[9] Mohammed Brahim,(Sustainable Development, Establishment of Makassedi, Center of Knowledge Enlightenment), 2007.

[10] Mohamed, Mohamed Khair,, (The Sudanese economy, the historical track and opportunities for future challenges, a reading of before and after the secession of the south, Khartoum.

[11] Mahmoud Taha,(Concept of Human Resources Development, First Human Resources Development Conference), Khartoum, July 2012

[12] Product Use and Employment of Graduates Project, Total and Sectoral Policies to Combat Unemployment among Mid-Term Graduates for the Years 2005-2008, June 2004.

[13] Mustafa Shafiq illiteracy Badran. Dimensions of Development in the Arab World (Amman, Dar Al Mustaqbal Publishing, 1995).

[14] Mustafa Hussein, Mohammed Shafiq and Umayya Badran. (Oman, Future House for Publishing, 1995).

[15] Nabil Khoury (Human Resources Development Policies in Arab Countries), Damascus, 2004.

[16] Nabila Hussein,(The entrances to human resources development), Dar Arabi Publishing, Cairo 2010.

[17] Nadia Said Mohamed, (The Role of Human Resources Development in Achieving Human Development Goals in Sudan, Unpublished Master Thesis), Al-Neelain University, 2012.

[18] Zaki Maki Ismail, Resource Management for Humanity, Sudan Press, Limited Currency, Khartoum, Iraq, 2, 2009. 